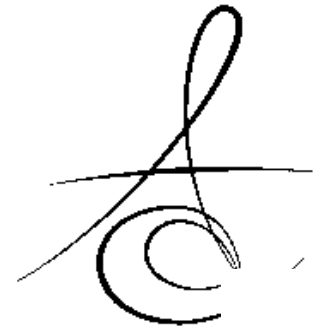

Doç. Dr. Resmiye Ebru TíRALi*

\section{ÇOCUK İSTİSMARI VE İHMALİNİN ORAL BULGULARI}

\author{
ORAL SYMPTOMS OF CHILD ABUSE AND NEGLECT
}

Yrd. Doç. Dr. Sıdıka Sinem SOYDAN**

Makale Kodu/Article code: 1264

Makale Gönderilme tarihi: 16.08 .2013

Kabul Tarihi: 28.11 .2013

\section{ÖZET}

Çocuk istismarı ve ihmali günümüzün en önemli problemleri arasında yer almaktadır. Vakaların yaklaşık yüzde ellisinde oro-fasiyal yaralanmanın görülebilmesinden dolayı, istismar ve inmal yaralanmalarının tanı, bildirme ve önlenmesinde dental profesyoneller önemli bir yere sahiptir. Bu derlemenin amacı çocuk ihmal ve istismarının tiplerinin, oral semptomlarının klinik bulgularının ve bu tür olgularda durum yönetiminin irdelenmesidir.

Anahtar kelimeler: Çocuk ihmali ve istismarı; oral bulgular; diş hekimliği

\section{ABSTRACT}

Child abuse and neglect is now recognized one of the most important problem of recent times. The findings suggest the importance of involving dental professionals in identifying, reporting, and preventing child abuse and neglect, because oro-facial trauma occurs in approximately half of all cases. This review includes a discussion of the types of child abuse and neglect, clinical presentation of oral symptoms and management of such issues.

Keywords: Child abuse and neglect, oral symptoms, dentistry

Türk toplumundaki ekonomik sorunlar ve çok çocukluluk, tek odalı evlerde yaşama, ataerkil aile yapısı, ebeveynlerin düşük eğitim düzeyi, çocuğa ve kadına uygulanan şiddetin kabul görmesi, cinsiyet ayrımcılığı, kızların erken yaşta evlendirilmesi, fiziksel şiddeti destekleyen "Dayak cennetten çıkmadır, kızını dövmeyen dizini döver" gibi topluma yerleşmiş sözler çocuk istismarı riskini arttırmaktadır. Diğer toplumlarda kültürel tolerans farklılıkları, fiziksel cezalandırmanın normal karşılanması, ebeveyn geçimsizlikleri, mutsuzhuzursuz aile ortamı, üvey ebeveyn ile yaşama, ruh ve beden sağlığının bozuk olma durumları olası nedenler arasında sayılmaktadır. ${ }^{7}$ Çocuk istismarının gerçekleşebilmesi için üç etkenin bir arada olması gerekir. Bunlar; uygun anne-baba, uygun çocuk ve uygun zaman (kriz dönemi) olarak sınıflandırılmaktadırlar. ${ }^{2}$

Çocuk istismarında adli tıp doktorları, sosyal pediatristler, çocuk ve ergen ruh sağlığı uzmanlarınca

*Başkent Üniversitesi, Diş Hekimliği Fakültesi, Pedodonti Anabilim Dalı

** Baskent Üniversitesi. Dis Hekimliăi Fakültesi. Aăız Dis ve Cene Cerrahisi Anabilim Dalı 
teşhis konmasının yanında oral kavitede bu istismarlara yönelik çok sayıda bulgu ve delil olduğundan diş hekimleri de teşhise katkıda bulunabilmektedir. Bu derlemenin amacl; çocuk hastaları da tedavi eden diş hekimlerini, çocuk istismarının oral bulgularının erken tanısını koyma ve uygun yaklaşımda bulunabilmek için bilgilendirmektir.

Çocuk istismarı fiziksel istismar, cinsel istismar, duygusal istismar ve ihmal olmak üzere dört türlüdür ve oral kavitede bulguları olabilmektedir.

\section{Fiziksel İstismarın Oral Bulguları:}

Fiziksel istismar çocuğun kaza dışı nedenlerle bedensel yaralanmasıdır. Ailesi tarafından çocuğa yeterince ilgi gösterilmemesine bağlı oluşabilecek kazalarda fiziksel istismara girmektedir. ${ }^{8}$

Fiziksel istismar olgularında öykü alınırken;

i) Elde edilen öykü mevcut yaralanmanın mekanizması ve boyutu ile uyuşuyor mu,

ii) Yaralanmanın, çocuğun bakımını üstlenen kişinin ifade ettiği gibi çocuğun kendi başına ya da bu tür olgularda sık karşılaşıldığı üzere çocuğun sorumluluğunun alındığı mekanda bulunan diğer çocuklar tarafından oluşturulabilecek düzeyde olup olmadığı,

iii) Klinik bulgular tıbbi nedenle açıklanabiliyor mu değerlendirilmelidir. ${ }^{9}$

Çocuklarda fiziksel istismarın oral bulguları ağız çevresi, dudak ve oral kavite içinde görülebilir. ${ }^{10}$ Fiziksel istismara maruz kaldığı düşünülen çocuğun yüz, ağız ve boğaz bölgesinin muayenesi diş hekimi tarafından kapsamlı bir şekilde yapılmalıdır.

Fiziksel istismara uğramış çocukların yüzlerinde ekimoz, sıyrık, yanık ve ısırık izleri olabildiği gibi, oral kavitede dişlerde ve oral mukozada da belirtiler bulunabilir. ${ }^{11}$ En çok tırnak ve yüzüklere bağlı orofasiyal yaralar oluşmaktadır.

Oral kavitede dil, yanak mukozası, sert ve yumuşak damak ve alveolar mukozada yanık ve ısırık izleri bulunabilir. Damak, vestibül ve ağız tabanındaki delici yaralanmalar, bebeklerde zorla yemek yedirme sırasında oluşabilir. ${ }^{7,10}$

Yüz bölgesine travma gelmesi sonucu frenulum ve üst dudakta laserasyonlar, diş avülsiyonları, pulpa nekrozları, diş-çene ve yüz kemiklerinde kırıklar görülebilir. Bu bulguların bir veya birkaçının varlığı fiziksel istismarı akla getirmelidir.

Oral mukoza yanıkları, çocuklara sıcak veya yakıcı sıvıların zorla verilmesi sonucu oluşabilir. Deride sıcak katı objeler bül formasyonu olmaksızın, sigara ise büllöz impetigoya benzer yaralar oluşturmaktadır. ${ }^{10}$

Fiziksel istismara uğrayan çocuklardaki kemik kırıkları en çok 3 yaş altında görülmektedir. Okul çağındaki çocuklarda kaza sonucu kırıklar oluşmaktadır. Fiziksel saldırı sonucu \%45 nazal kırıklar, \%32 mandibuler kırıklar ve \%20 oranla da zygomaticomaksillerkompleks ile orbita kırıkları görülmektedir. ${ }^{10}$

\section{Cinsel İstismarın Oral Bulguları:}

Çocuklarda oral kavite cinsel istismara sık maruz kalan bir bölgedir. Cinsel istismar olgularında diş hekimi ile konsültasyon gerekebilmektedir.

Çocukta cinsel yolla bulaşan hastalıkların oral bulguları 2 yaşın altında görüldüğünde intrauterin veya perinatal dönemde bulaşma intimalini akla getirmelidir. 2-10 yaş arasında bu bulguların varlığında ise ilk akla gelen cinsel istismar olmalıdır. ${ }^{11}$

Oral veya perioral gonore, herpes simpleks, treponema pallidium veya sifiliz lezyonlarının bulunması prepubertal bir çocukta cinsel istismar için belirleyici bulgudur.,12,13 Gonore yüz, dudaklar, ağız ve farinkste eritemli ve ülseratif lezyonlar veya gonokokal stomatitler şeklinde görülebilir. Frengi dudaklarda veya diş etinde şankrlar şeklinde lezyonlar oluşturabilir.

Damağın arka kısmında veya dilaltında ekimoz penisin oral penetrasyonunun bir belirtisi olabilir. ${ }^{11}$ Oral kavitede kıl veya meni kalıntıları mutlaka akla cinsel istismarı getirmelidir. Bu şüphe varlığında ağız mukozası ve dil yüzeyinden swap almak bulguların doğruluğunu belirlemek açısından önemlidir. Diş hekimi bir girişimde bulunmadan önce bu bulguları göz ardı etmemelidir.

Perioral bölgede travmatik öpmeye bağlı ekimoz ve hematom görülebilir. Dudaklarda şiddetli basınca bağlı laserasyonlar ve dişlerde abrazyonlar oluşabilir. Oral bölgede görülen ısırık izleri cinsel istismar veya kavga sırasında meydana gelebilir. Eğer bir çocuk başka bir çocuk tarafından ısırılmışsa genellikle ısırık izi üst ekstremite bölgesindedir, bir yetişkin tarafından yapılan istismar içerikli bir ısırık genital bölgede veya dudaklarda görülmektedir. ${ }^{14}$

\section{Duygusal İstismarın Oral Bulguları}

Çocukta stres ve şiddete bağlı bruksizm ve eklem problemleri görülebilir. İlgi eksikliği parmak emme, tırnak yeme veya diş gıcırdatma gibi habitüel alışkanlıklar gelişmesine neden olabilir. Bu habitüel 
alışkanlıklar dental ve iskeletsel malokluzyonlara ve dental hasarlara yol açabilir (Resim 1).

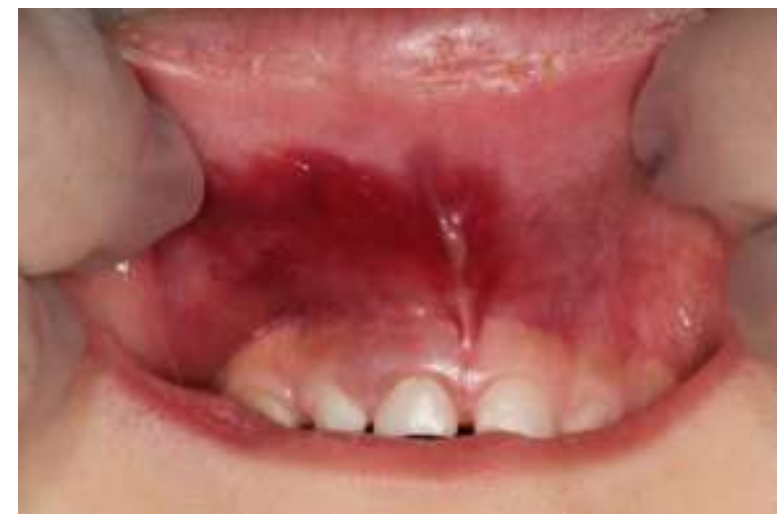

Resim 1 Uzamış emzik kullanımı alışkanlığı olan çocuk hastada ağızda emzik varken düşmeye bağlı oluşmuş vestibül mukoza ekimozu.

\section{Dental Íhmal:}

Çocuklarda diş çürükleri, yetersiz dental hijyen ve periodontal hastalıklar tedavi edilmediği takdirde ağrı, enfeksiyon ve fonksiyon kaybı gibi sonuçlar doğurur (Resim 2). Bu kayıplar büyüme gelişimi ve çevreyle olan ilişkiyi olumsuz yönde etkiler. ${ }^{15,16} \mathrm{Bu}$ ihmal ebeveynlerin kendi içindeki sorunları, ilgi yetersizliği veya sosyo ekonomik sıkıntılar nedeniyle oluşabilir. ${ }^{17}$

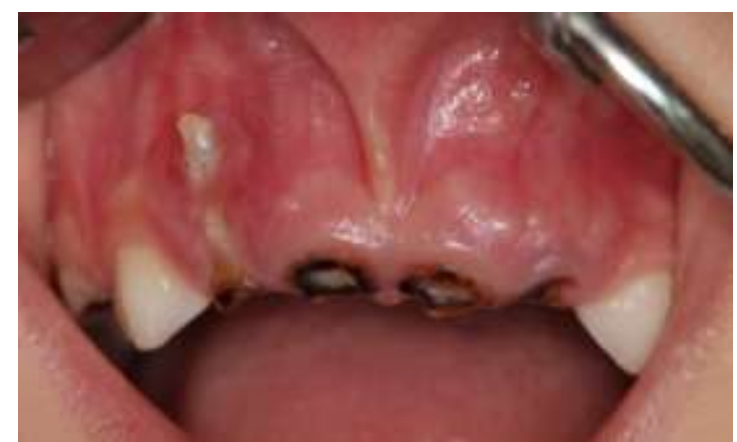

Resim 2 İhmale bağlı dental hijyen eksikliği ve çoklu çürük görülmesi.

\section{SONUC}

Tüm çocuk istismarlarında çok çeşitli oral bulgular olabileceğinden, ayrıntılı oral muayene gereklidir. Ağız-diş sağlığı ve dental hasarları tanıma konusunda hekimlerin klinik deneyimlerinin yetersiz olması çocuk istismarının oral bulgularını gözden kaçırımasına neden olabilir. $\mathrm{Bu}$ nedenle diş hekimlerine çocuk istismarının oral bulgularını tanımada büyük sorumluluk düşmektedir. Yapılan çalışmalar diş hekimlerinin eğitiminde, fiziksel istismara uğramış çocuğu koruma servislerine yönlendirmek için sorumluluk alma konusunda eksiklikler olduğunu göstermiştir. Diş hekimlerinin öğrenimleri sonrasında da çocuk istismarının oral bulgularını tanımaya yönelik eğitim almaları ve bu bulgularla karşılaştıkları takdirde Türk Ceza Kanunu'nun 278-279-280. maddelerine göre adli birimlere bildirmeleri gerekmektedir.

Diş hekimlerinin çocuk fiziksel istismarının belirlenmesindeki yardımları: 1. Fiziksel istismarın tanınması, 2. Temel acil dental tedavinin sağlanması 3. İleri tedavinin planlanması 4. Şüpheli vakaların ilgili birimlere bildirilmesi olarak sıralanabilir.

\section{KAYNAKLAR}

1. Kara B, Biçer Ü,Gökalp AS. Çocuk İstismarı. Çocuk Sağlığı ve Hastalıkları Dergisi 2004;47:140-51.

2. Kaya A. Çocuğa Yönelik Şiddette; Çocuk, Ebeveyn ve Eğiticilerin Algı Farkındalığının Değerlendirilmesi. Uzmanlık Tezi, Ege Üniv Tıp Fak Adli Tıp Anabilim Dalı, 2010.

3. Jain AM. Emergency department evaluation of child abuse. Emerg Med Clin Nort Am 1999;17:575-93.

4. Practice parameters for the forensic evaluation of children and adolescents who may have been physically or sexually abused. J Am Acad Child Adolesc Psychiatry 1997;36:37-56.

5. Dubowitz H. Preventing child neglect and physical abuse. Pediatr Rev 2002;23:191-6.

6. Bilir Ş, Arı M, Dönmez $N$ ve ark. 4-12 Yaşları Arasında 16.100 Çocukta Örselenme Durumları ile İlgili Bir İncelenme. Çocuk İstismarı ve İhmali, Çocukların Kötü Muameleden Korunması. I. Ulusal Kongresi, Ankara. Gözde Repro Ofset 1991:45-53.

7. Şimşek $F$, Ulukol B, Bingöler B. Çocuk İstismarına Disiplin Penceresinden Bakış. Adli Bilimler Dergisi. 2004;31:47-52.

8. İzmirli $M$, Polat $N$. Çocuk İstismarı ve İhlali. Çocuk Forumu Dergisi. Nisan-Mayıs-Haziran Cilt 4, 2001:2. 
9. Topbaş M. İnsanlığın Büyük Ayıbı. Çocuk İstismarı. TSK Koruyucu Hekimlik Bülteni. 2004;3:76-80.

10. Andressen JO, Andressen FM, Andersson L. Textbook and Color Atlas of Traumatic Injuries to the Teeth. Child Physical Abuse. 4th ed, London, Wiley - Blackwell; 2010.

11. Yaşarı ZF, Gültekin Akduman G. Çocuk İhmalİstismarı ve Adli Diş Hekimliği. TSK Koruyucu Hekimlik Bülteni 2007;6:389-94.

12. Tercier A. Child Abuse. In: Maer JA. Emergency Medicine. 4th ed., St. Louis, Mosby; 1998.

13. Kairys SW, Alexander RC, Block RW et al. Oral and Dental Aspects of Child Abuse and Neglect. Pediatrics 1999;104:644-5.

14. 14.Dominguez RZ, Nelke CF, Perry BD. Child Trauma Academy-Sexual Abuse of Children. 2001. http://www.aaets.org/article124.htm

15. California Society of Pediatric Dentistr. Dental Neglect: When to report. California Pediatrician 1989:31-2.

16. Kellogg N. The Committee on Child Abuse and Neglect. Oral and Dental Aspects of child abuse and Neglect. Pediatrics 2005;116:1565-8.

17. Sanger RG, Bross DC. Clinical Management of Child Abuse And Neglect: A Guide for the Dental Professional. Chicago, IL: Quintessence Publishing Co, Inc; 1984.

\section{Yazışma Adresi:}

Yrd. Doç. Dr. Sıdıka Sinem Soydan

Başkent Üniversitesi, Diş Hekimliği Fakültesi, Ağız Diş ve Çene Cerrahisi Anabilim Dalı Adres: 11. Sokak no:26 Bahçelievler, Çankaya, Ankara Telefon:03122151336

Faks:03122122962

e-mail:sdksoydan@yahoo.com 